\title{
The Preconditioning of Berberine Suppresses Hydrogen Peroxide-Induced Premature Senescence via Regulation of Sirtuin 1
}

\author{
Xiaofei Zhu, ${ }^{1,2,3}$ Haodi Yue, ${ }^{1}$ Xiaofang Guo, ${ }^{4}$ Jingyi Yang, ${ }^{1}$ Jingshuo Liu, ${ }^{1}$ Jiangtao Liu, ${ }^{1}$ \\ Ruijie Wang, ${ }^{1}$ and Wenjuan $\mathrm{Zhu}^{1}$ \\ ${ }^{1}$ Department of Clinical Immunology, Research Center for Immunology, School of Laboratory Medicine, Xinxiang Medical \\ University, Xinxiang 453003, China \\ ${ }^{2}$ Henan Collaborative Innovation Center of Molecular Diagnosis and Laboratory Medicine, Xinxiang Medical University, \\ Xinxiang 453003, China \\ ${ }^{3}$ Xinxiang Assegai Medical Laboratory Institute, Xinxiang Medical University, Xinxiang 453003, China \\ ${ }^{4}$ Department of Microbiology, School of Basic Medical Sciences, Xinxiang Medical University, Xinxiang 453003, China
}

Correspondence should be addressed to Xiaofei Zhu; zhuxf@xxmu.edu.cn

Received 20 April 2017; Accepted 23 May 2017; Published 2 July 2017

Academic Editor: Isabel C. F. R. Ferreira

Copyright (C) 2017 Xiaofei Zhu et al. This is an open access article distributed under the Creative Commons Attribution License, which permits unrestricted use, distribution, and reproduction in any medium, provided the original work is properly cited.

\begin{abstract}
With a long history of application in Chinese traditional medicine, berberine (BBR) was reported to exhibit healthspan-extending properties in some age-related diseases, such as type 2 diabetes and atherosclerosis. However, the antiaging mechanism of $\mathrm{BBR}$ is not completely clear. By means of hydrogen peroxide- $\left(\mathrm{H}_{2} \mathrm{O}_{2}-\right)$ induced premature cellular senescence model, we found that a lowconcentration preconditioning of BBR could resist premature senescence in human diploid fibroblasts (HDFs) measured by senescence-associated $\beta$-galactosidase (SA- $\beta$-gal), accompanied by a decrease in loss of mitochondrial membrane potential and production of intracellular reactive oxygen species (ROS). Moreover, the low-concentration preconditioning of BBR could make cells less susceptible to subsequent $\mathrm{H}_{2} \mathrm{O}_{2}$-induced cell cycle arrest and growth inhibition. Experimental results further showed that the low concentration of BBR could induce a slight increase of ROS and upregulate the expression level of sirtuin 1 (SIRT1), an important longevity regulator. $\mathrm{H}_{2} \mathrm{O}_{2}$-induced activation of checkpoint kinase 2 (Chk2) was significantly attenuated after the preconditioning of BBR. The present findings implied that the low-concentration preconditioning of BBR could have a mitohormetic effect against cellular senescence triggered by oxidative stress in some age-related diseases through the regulation of SIRT1.
\end{abstract}

\section{Introduction}

Since the "free radical theory" was proposed by Harman in 1956, it is gradually recognized that excessive ROS, a potent inducer of cellular senescence, are implicated in a variety of age-related diseases, including cardiovascular disease, type 2 diabetes and Alzheimer's disease [1, 2]. Mitochondria are not only a major resource of cellular ROS generation but also a sensitive target for oxidative damage. Mitochondria damage induced by ROS could be indicated by loss of electron transport, mitochondrial membrane potential, and ATP generation, which could suggest respiratory dysfunction that exacerbate ROS generation and lead to the "vicious cycle" [3]. As the major ROS within cells, $\mathrm{H}_{2} \mathrm{O}_{2}$ is regarded as a key source of hydroxyl radical modifying and mutating mitochondrial DNA (mtDNA), which was proved to be associated closely with premature aging. Experimental evidence also proved that exposure of young HDFs to subcytotoxic concentration of $\mathrm{H}_{2} \mathrm{O}_{2}$ accelerated cellular senescence, which displays several replicative senescent-like features including senescenceassociated $\beta$-galactosidase (SA- $\beta$-gal) activity, an irreversible growth arrest in G1 and change in expression level of many genes [4-6]. 
Berberine (BBR) is a botanical alkaloid and the major bioactive compound in the Chinese's herb Rhizoma coptidis, which had been utilized to treat diabetes and infection for decades in traditional Chinese medicine [7, 8]. Recently, it was reported that BBR could exhibit a lifespan-prolonged function by influencing the conversion of tryptophan into kynurenine in Drosophila [9]. Meanwhile, BBR was also proposed as a potential antiaging agent in oxidative DNA damage and could affect mitoxantrone-induced cellular senescence $[10,11]$. But the antisenescence mechanism of BBR is still not very clear. Previously, we observed that BBR was able to protect hepatocytes from $\mathrm{H}_{2} \mathrm{O}_{2}$-induced cellular apoptosis by SIRT1 [12], which is $\mathrm{NAD}^{+}$-dependent histone deacetylase, and plays an important role in the lifespanextending effect of caloric restriction and antiaging as the longevity regulator $[13,14]$. Indeed, excessive ROS, especially $\mathrm{H}_{2} \mathrm{O}_{2}$, could accelerate cellular senescence by affecting the function and expression level of SIRT1 $[15,16]$. In this study, we wanted to confirm the hypothesis that $\mathrm{BBR}$ may be against $\mathrm{H}_{2} \mathrm{O}_{2}$-induced premature senescence by SIRT1 and explore the possible pharmacological mechanism of BBR involved with the regulation of SIRT1 in order to expand its potential application for age-related diseases.

\section{Materials and Methods}

2.1. Materials. Human fetal lung diploid fibroblast cell line 2BS was purchased from the Institute of Basic Medical Sciences, Chinese Academy of Medical Sciences. Berberine and dimethyl sulfoxide (DMSO) were obtained from SigmaAldrich Chemical Inc. (St. Louis, MO, USA). 3-(4,5dimethyl-2-thiazolyl)-2,5-diphenyl-2H-tetrazolium bromide (MTT) was purchased from Promega (Beijing) Biotech Co., Ltd. ROS Detection Reagents $\mathrm{H}_{2}$ DCFDA was from Molecular Probes (Molecular Probes, Eugene, OR, USA). Hydrogen peroxide was a product of Beijing Chemicals Reagent Co., Ltd (Beijing, China). Dulbecco's modified Eagle's medium (DMEM) with high glucose and fetal bovine serum were from Invitrogen (Carlsbad, CA, USA). Antibodies against Phospho-Chk2(\#2661), Chk2(\#3440),

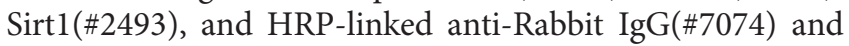
anti-Mouse IgG(\#7076) were obtained from Cell Signaling Technology (Beverly, MA, USA), anti-actin antibody (sc1616R) was from Santa Cruz Biotechnology (Santa Cruz, CA, USA), and ECL plus Western blotting kit was from GE Healthcare Bio-Sciences (Marlborough, MA, USA).

2.2. Cell Culture. The characters and application of human diploid fibroblasts for cellular senescence research have been reported [16]. Briefly, early passage $2 \mathrm{BS}$ in 20 population doublings (PDs) were cultured in DMEM supplemented with $10 \%$ fetal bovine serum, $100 \mathrm{IU} / \mathrm{mL}$ penicillin, and $100 \mu \mathrm{g} / \mathrm{mL}$ streptomycin at $37^{\circ} \mathrm{C}$ in a humidified atmosphere of $5 \% \mathrm{CO}_{2}$ and $95 \%$ air. According to different experiment requirements, $2 \mathrm{BS}$ cells were seeded into plates at an appropriate density. When confluent, 2BS cells were preincubated with the indicated concentrations of BBR for $12 \mathrm{hr}$ before $\mathrm{H}_{2} \mathrm{O}_{2}$ was added to the medium. The $\mathrm{H}_{2} \mathrm{O}_{2}$ was freshly prepared from $30 \%$ stock solution and added to the culture medium at a final concentration of $200 \mu \mathrm{M}$.

2.3. Cell Cycle Assay. 20 PDs 2BS cells were seeded into 6-well plates at a density of $4 \times 10^{5} /$ well and cultured till confluence. After being synchronized by serum deprivation, cells were pretreated with or without BBR $(12 \mu \mathrm{M})$ for $12 \mathrm{hr}$ under normal serum conditions and exposed to $200 \mu \mathrm{M} \mathrm{H}_{2} \mathrm{O}_{2}$ for $2 \mathrm{hr}$. After that, cells were switched to fresh DMEM medium for $12 \mathrm{hr}$, digested by trypsin-EDTA, and collected by centrifuging at $1000 \mathrm{rpm}$ for $5 \mathrm{~min}$. Supernatant was discarded and cells were fixed in ice-cold $70 \%$ ethanol for $24 \mathrm{hr}$. At the time of analysis, cells were washed twice with PBS and then resuspended in $500 \mu \mathrm{L}$ PBS with $50 \mu \mathrm{g} / \mathrm{mL}$ propidium iodide and $100 \mu \mathrm{g} / \mathrm{mL}$ RNase A. After being incubated at $37^{\circ} \mathrm{C}$ for $30 \mathrm{~min}$ in the dark, DNA contents were analyzed for fluorescence with a BD FACSCalibur ${ }^{\mathrm{TM}}$ flow cytometer.

2.4. Senescence-Associated $\beta$-Galactosidase Staining. Cellular senescence was identified with $\beta$-galactosidase staining as described previously [6]. Briefly, after confluence, 2BS cells were pretreated with 6,12 , and $20 \mu \mathrm{M}$ BBR for $12 \mathrm{hr}$ before a $2 \mathrm{hr}$ exposure of $200 \mu \mathrm{M} \mathrm{H}_{2} \mathrm{O}_{2}$. Next, cells were passaged at a ratio of $1: 3$ to 6-well plates with fresh DMEM medium for four days and then washed twice in PBS, fixed for 3 5 min with 3\% formaldehyde, and washed with PBS again. After that, cells were incubated overnight at $37^{\circ} \mathrm{C}$ without $\mathrm{CO}_{2}$ in a freshly prepared staining buffer $(1 \mathrm{mg} / \mathrm{ml} \mathrm{X}$-gal, $40 \mathrm{mM}$ citric acid/sodium phosphate, $\mathrm{pH} 6.0,5 \mathrm{mM}$ potassium ferrocyanide, $5 \mathrm{mM}$ potassium ferricyanide, $150 \mathrm{mM}$ $\mathrm{NaCl}$, and $2 \mathrm{mM} \mathrm{MgCl}_{2}$ ).

2.5. Intracellular Reactive Oxygen Species (ROS) Assay. 20 PDs 2BS cells were cultured to reach confluence in 6-well plates and treated with $12 \mu \mathrm{M}$ BBR for $12 \mathrm{hr}$ prior to a $2 \mathrm{hr}$ exposure of $200 \mu \mathrm{M} \mathrm{H}_{2} \mathrm{O}_{2}$, or only treated with

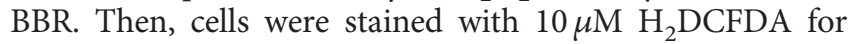
$30 \mathrm{~min}$ according to the manufacturer's manual. Oxidation of the probes to $2^{\prime}, 7^{\prime}$-dichlorofluorescein (DCF) was measured by $\mathrm{BD}$ FACSCalibur flow cytometry. Mean fluorescence intensity (MFI) was calculated and analyzed by CellQuest software. The percentage of ROS generation was calculated according to MFI value of DCF.

2.6. Measurement of Mitochondrial Membrane Potential $(\Delta \Psi m)$. To study the $\Delta \Psi \mathrm{m}$ changes, cells were stained with Rh123 at a final concentration of $10 \mu \mathrm{g} / \mathrm{mL}$ for $30 \mathrm{~min}$ in the dark, washed with PBS twice, and then centrifuged at $500 \times \mathrm{g}$ for $10 \mathrm{~min}$. Finally, fluorescence of Rh123 was immediately detected by BD FACSCalibur flow cytometry. Mean fluorescence intensity (MFI) was calculated and analyzed using CellQuest software. The percentage of mitochondrial membrane potential loss was calculated according to MFI value.

2.7. Western Blot. 2BS cells were washed with ice-cold PBS and collected by scraping, immediately lysed in RIPA buffer (10 mM Tris- $\mathrm{HCl} \mathrm{pH} 7.4,1 \%$ Triton X-100, 1\% sodium deoxycholate, $0.1 \%$ SDS, $160 \mathrm{mM} \mathrm{NaCl}, 5 \mathrm{mM}$ EDTA, 


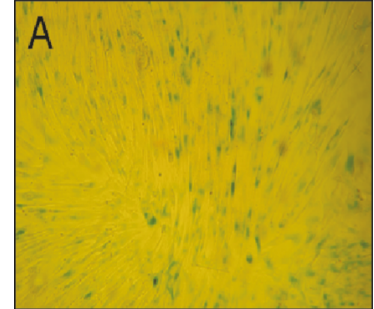

(a)

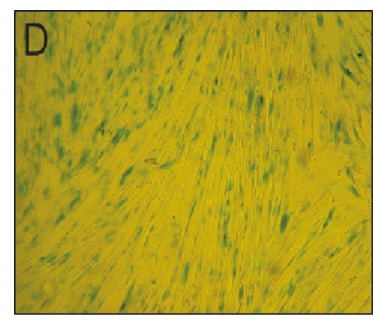

(d)

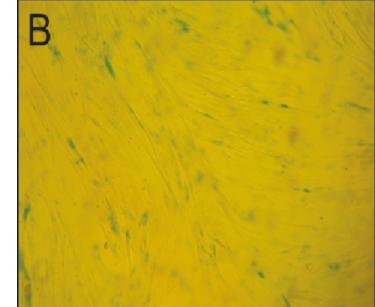

(b)

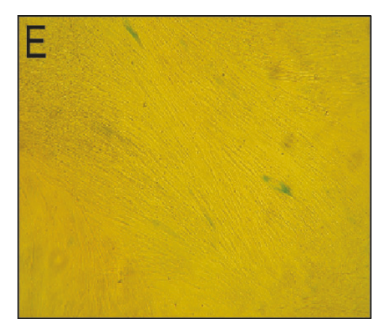

(e)

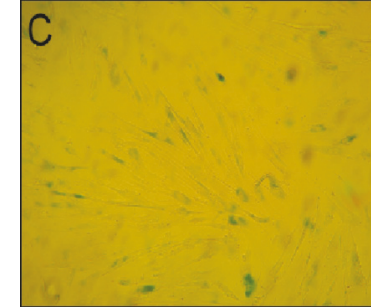

(c)

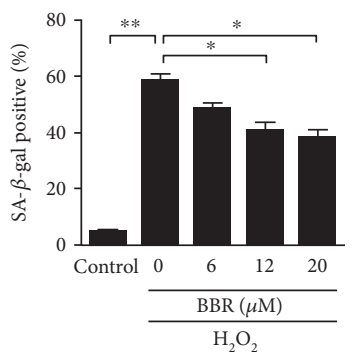

(f)

FIgURE 1: Antisenescence effect of $\mathrm{BBR}$ on $\mathrm{H}_{2} \mathrm{O}_{2}$-induced premature senescence in human diploid fibroblasts by $\beta$-galactosidase staining. $2 \mathrm{BS}$ cells were pretreated with different concentrations of BBR for $12 \mathrm{hr}$ before exposure to $200 \mu \mathrm{mol} / \mathrm{L} \mathrm{H}_{2} \mathrm{O}_{2}$. For senescence assay, cells were cultured for four days with new fresh DMEM medium. On the fifth day, the blue precipitate can be seen by X-gal dye in senescent cells as the Materials and Methods mentioned. (a), (b), and (c) Pretreatment with 6, 12, and $20 \mu \mathrm{mol} / \mathrm{L}$ BBR, respectively. (d) $\mathrm{H}_{2} \mathrm{O}_{2}$ treatment alone. (e) Untreated control. (f) The positive rates of SA- $\beta$-gal were calculated by counting the blue-dyed cells with a total of 200 cells at each visual field. ${ }^{*} p<0.05,{ }^{* *} p<0.01$. The results are representative of three separate experiments.

$50 \mathrm{mM} \mathrm{NaF}, 10 \%$ glycerol, $1 \mathrm{mM} \mathrm{Na} \mathrm{VO}_{4}$, and $5 \mathrm{mM}$ sodium pyrophosphate) supplemented with $1 \mu \mathrm{g} / \mathrm{mL}$ aprotinin, $10 \mu \mathrm{g} / \mathrm{mL}$ leupeptin, and $1 \mathrm{mmol} / \mathrm{L}$ phenylmethylsulfonyl fluoride. The protein concentration of extracts was determined by Bradford assay. According to the relative molecular weight of interest proteins, equal amounts of protein samples were subjected to 6-15\% SDS-PAGE and transferred onto PVDF membranes. The membranes were incubated with various antibodies at 1:1000 dilutions. Finally, they were incubated with horseradish peroxidaseconjugated secondary antibodies $(1: 2000)$. Visualization was detected with ECL Plus Western blotting Detection System according to the manufacturer's recommendation.

2.8. Statistical Analysis. Data are expressed as mean \pm SEM, and differences between two groups were assessed by the Student $t$-test. Differences between multiple groups were assessed by one-way ANOVA (Tukey's test). $p<0.05$ was considered significant.

\section{Results}

3.1. Berberine Attenuate $\mathrm{H}_{2} \mathrm{O}_{2}$-Induced Premature Senescence. Sublethal concentration $\mathrm{H}_{2} \mathrm{O}_{2}(<300 \mu \mathrm{M})$ could cause growth arrest and promote cellular senescence but no adverse effect on human diploid fibroblasts survival $[4,6]$. To investigate the effect of BBR on cellular senescence, we constructed the model of premature senescence via human fetal lung fibroblasts 2BS exposed to $200 \mu \mathrm{M} \mathrm{H}_{2} \mathrm{O}_{2}$. As showed in Figure $1(\mathrm{~d}), \mathrm{H}_{2} \mathrm{O}_{2}$ obviously induced premature cellular senescence indicated by a $58.6 \pm 2.4 \%$ of SA- $\beta$-gal-positive cells compared with control group indicated by $4.8 \% \pm 0.8 \%$ (Figure 1(e)). Meanwhile, $\mathrm{H}_{2} \mathrm{O}_{2}$ also induced significantly $92.2 \pm 1.29 \%$ G1 phase arrest compared with $68.4 \pm 2.5 \%$ of control (Figures 2(a) and 2(b)). However, the preconditioning of different concentrations of BBR (6-20) exhibited a significant reduction in the proportion of SA- $\beta$-gal-positive cells from $58.6 \pm 2.4 \%$ to $48.8 \pm 1.9 \%, 40.8 \pm 3.0$, and $38.1 \pm 3.15$, respectively (Figures $1(\mathrm{a}), 1(\mathrm{~b}), 1(\mathrm{c})$, and $1(\mathrm{f})$ ). In addition, the preconditioning of BBR at $12 \mu \mathrm{M}$ partially rescued $\mathrm{H}_{2} \mathrm{O}_{2}$ induced change of cell cycle from $92.2 \pm 1.29 \%$ to $80.6 \pm 2.5 \%$ in G1 phase, $2.2 \pm 0.52 \%$ to $8.5 \pm 1.1 \%$ in $S$ phase, and 5.5 $\pm 0.78 \%$ to $8.8 \pm 1.5 \%$ in $\mathrm{G} 2 / \mathrm{M}$ phase (Figures $2(\mathrm{a})$ and $2(\mathrm{~b})$ ). Also, the preconditioning of BBR at $12 \mu \mathrm{M}$ significantly prevented $\mathrm{H}_{2} \mathrm{O}_{2}$-induced inhibition of cell growth from 41.8 $\pm 1.7 \%$ to $21.1 \pm 4.5 \%$. Interesting, when the concentration of BBR pretreated was $20 \mu \mathrm{M}$, the cytoprotective effect of BBR was absent (Figure S1 available online at https://doi.org/10. $1155 / 2017 / 2391820)$. These results suggested that lowconcentration preconditioning of BBR had a beneficial effect on fibroblasts for resisting $\mathrm{H}_{2} \mathrm{O}_{2}$-induced cellular senescence.

3.2. Berberine Protect $\mathrm{H}_{2} \mathrm{O}_{2}$-Induced Damage of Mitochondrial Membrane. To examine the protective effect of BBR on mitochondrial membrane, Rhodamin 123 was utilized for staining cells, which could selectively be retained in the mitochondria with an intact membrane potential, and be washed out of cells when mitochondrial membrane potential is lost [17, 18]. As shown in Figure $3, \mathrm{H}_{2} \mathrm{O}_{2}$ obviously induced an increase of $2 \mathrm{BS}$ cells with $\Delta \Psi \mathrm{m}$ loss from $6.7 \pm 0.64 \%$ to $36.6 \pm 4.5 \%$. Indeed, pretreatment of BBR at $12 \mu \mathrm{M}$ decreased the percentage of $2 \mathrm{BS}$ cells with $\Delta \Psi \mathrm{m}$ loss from 

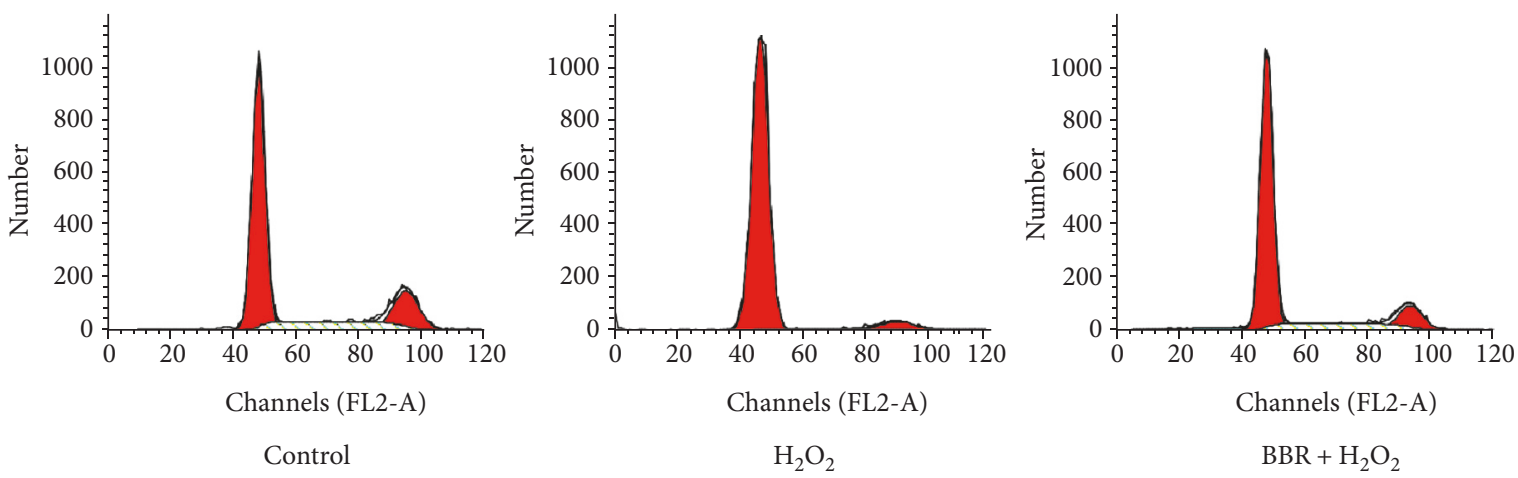

(a)

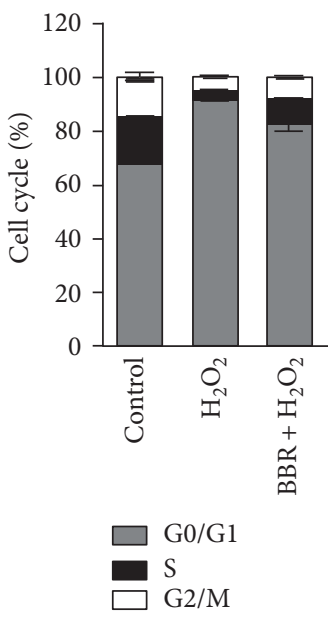

(b)

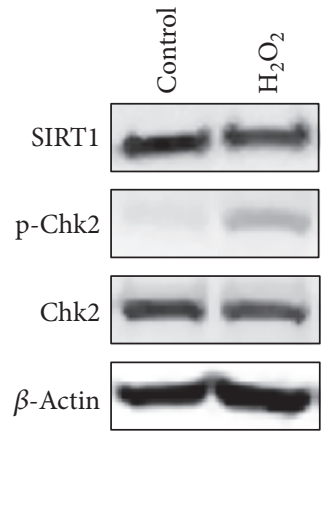

(c)
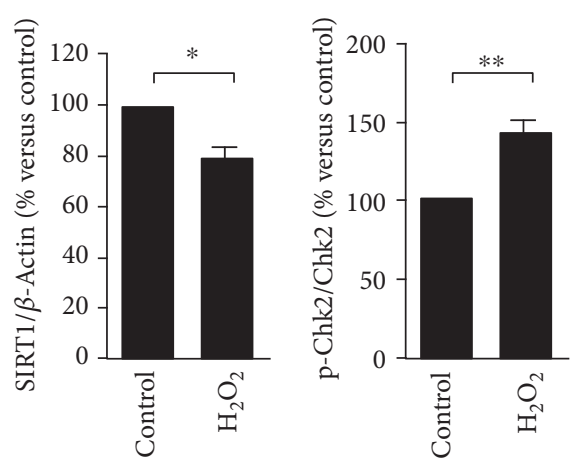

(d)

Figure 2: Cell cycle arrest and protein expression of $\mathrm{H}_{2} \mathrm{O}_{2}$-induced premature senescence in human diploid fibroblasts. 2BS cells were exposed to a sublethal concentration of $200 \mu \mathrm{mol} / \mathrm{L} \mathrm{H}_{2} \mathrm{O}_{2}$, or pretreated with $12 \mu \mathrm{mol} / \mathrm{L}$ BBR for 12 hr before exposure. (a), (b) The influence of BBR in $\mathrm{H}_{2} \mathrm{O}_{2}$-induced cell cycle distribution. (c) The changes of SIRT1 expression and phosphorylation of Chk2 in $\mathrm{H}_{2} \mathrm{O}_{2}$ exposed human diploid fibroblasts. (d) Relative expression levels of Sirt1 and phospho-Chk2 in $\mathrm{H}_{2} \mathrm{O}_{2}$-exposed human diploid fibroblasts by gray analysis. ${ }^{*} p<0.05,{ }^{* *} p<0.01$. The results are representative of three separate experiments.

$36.6 \pm 4.5 \%$ to $13 \pm 2.7 \%$. Moreover, $\mathrm{H}_{2} \mathrm{O}_{2}$ exposure led to a significant increase to $21.1 \pm 1.8 \%$ in intracellular ROS of $2 \mathrm{BS}$ cells by fluorescent probe DCF, compared with $3.4 \pm 0.57 \%$ of untreated control. The percentage of intracellular ROS induced by $\mathrm{H}_{2} \mathrm{O}_{2}$ reduced obviously from 21.1 $\pm 1.8 \%$ to $9.4 \pm 0.9 \%$ after the preconditioning of $\mathrm{BBR}$ at $12 \mu \mathrm{M}$. Interestingly, BBR itself caused a slight increase in intracellular ROS generation $(4 \pm 1.6 \%)$, but nonsignificantly compared with untreated control (Figure 4). These data implied that the low-concentration preconditioning of BBR against $\mathrm{H}_{2} \mathrm{O}_{2}$-induced cellular senescence could be closely associated with BBR-induced mitochondrial stress, which subsequently plays an important role in the resistance of sublethal $\mathrm{H}_{2} \mathrm{O}_{2}$-induced damage.

3.3. Berberine Upregulates SIRT1 Expression and Reduces $\mathrm{H}_{2} \mathrm{O}_{2}$-Induced Chk2 Activation. As our previous report, BBR could influence the survival of cells by an important longevity regulator SIRT1 [12]. Therefore, we examined the role of SIRT1 in $\mathrm{H}_{2} \mathrm{O}_{2}$-induced premature senescence of human diploid fibroblasts $2 \mathrm{BS}$. As shown in Figure 2, $\mathrm{H}_{2} \mathrm{O}_{2}$ exposure for $2 \mathrm{hr}$ induced a moderate decrease of SIRT1 expression in 2BS cells. When cells were exposed to $\mathrm{H}_{2} \mathrm{O}_{2}$ for $4 \mathrm{hr}$, the expression level of SIRT1 exhibited a significant reduction (Figure 5). It was interesting that BBR at $12 \mu \mathrm{M}$ alone could upregulate SIRT1 expression of fibroblasts 2BS in a time-dependent manner (Figure S2). $\mathrm{H}_{2} \mathrm{O}_{2}$ exposure also activated checkpoint kinase 2 significantly in a timedependent manner (Figure 5), which is an event of the molecular signalling in $\mathrm{H}_{2} \mathrm{O}_{2}$-induced DNA damage response [19]. However, the preconditioning of BBR could not only protect from reduction of expression level of SIRT1 as same as did in our previous report, but also reduce phosphorylation of Chk2 (Figure 5). Meaningfully, the changes between SIRT1 expression and Chk2 phosphorylation by the preconditioning of $\mathrm{BBR}$ were inverse. These results hinted that the protective effect of low-concentration preconditioning of BBR on mitochondria or cellular senescence may be related to the upregulation of SIRT1 and deactivation of Chk2.

\section{Discussion}

Despite organismal complexity, the knowledge of basic aging or senescence mechanisms had been updated constantly for 


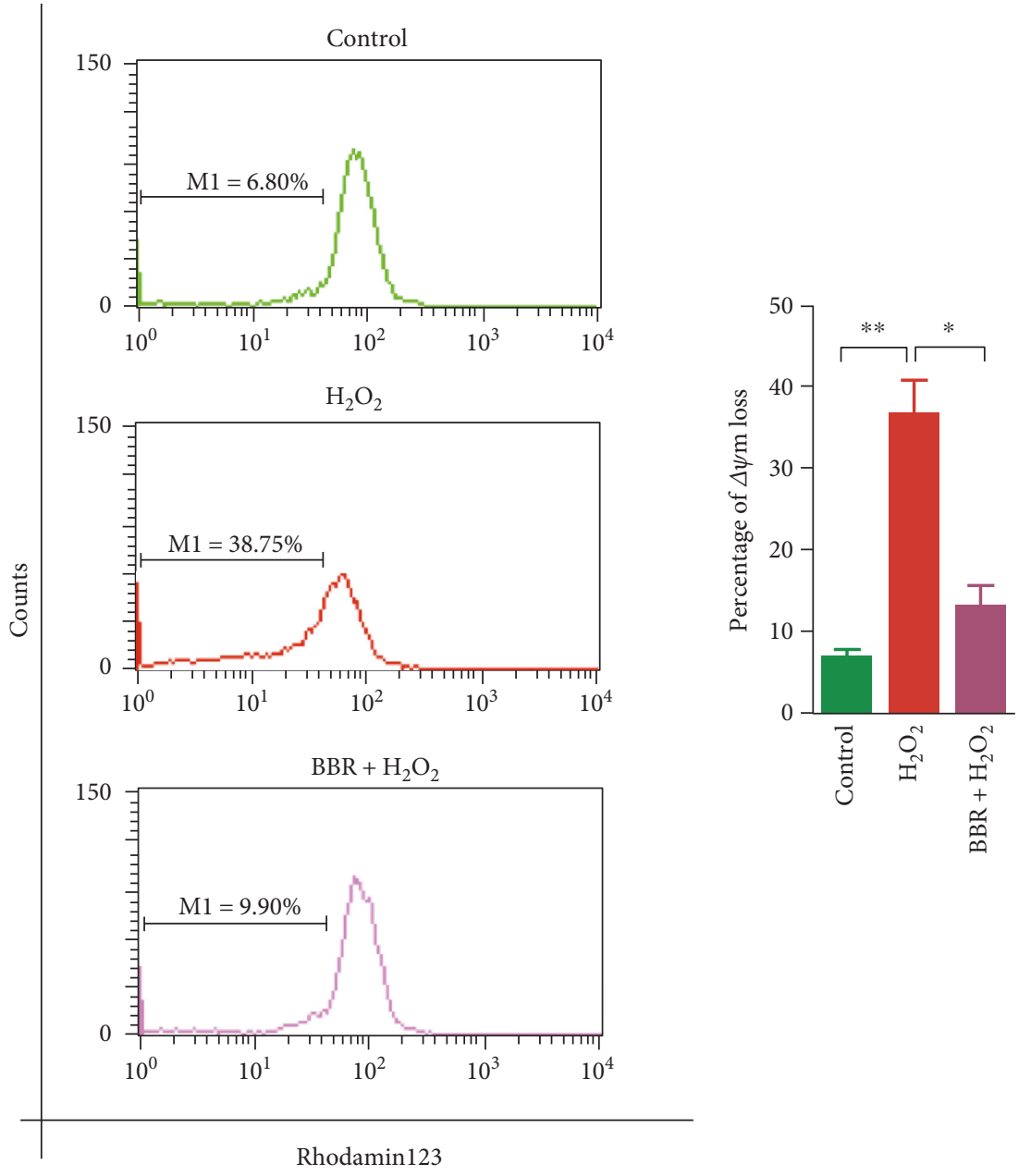

(a)

(b)

FIgURE 3: Protective effect of BBR on $\mathrm{H}_{2} \mathrm{O}_{2}$-induced mitochondrial membrane potential $(\Delta \psi \mathrm{m})$ loss in human diploid fibroblasts. 2BS cells were pretreated with or without $12 \mu \mathrm{mol} / \mathrm{L}$ BBR for $12 \mathrm{hr}$ before a $2 \mathrm{hr}$ exposure to $200 \mu \mathrm{mol} / \mathrm{L}_{2} \mathrm{O}_{2}$ and then were stained with Rhodamin123. (a) The diagram from flow cytometry test. M1 represents the percentage of $\Delta \psi \mathrm{m}$ loss. (b) Histogram of the mean fluorescence intensity of M1. ${ }^{*} p<0.05,{ }^{* *} p<0.01$. The results are representative of three separate experiments.

decades of research from cell-tissue culture to model organisms. Extending lifespan by biomedical interventions are scientifically plausible, such as calorie restriction and pharmacologically proaging pathway-targeted drugs $[20,21]$. Here, we showed that a low concentration of BBR at $12 \mu \mathrm{M}$ could upregulate the expression level of SIRT1, an important longevity regulator, in human diploid fibroblasts, and the preconditioning of BBR at $12 \mu \mathrm{M}$ could suppress $\mathrm{H}_{2} \mathrm{O}_{2}$ induced cellular senescence by deactivating checkpoint kinase 2, which may subsequently prevent the downregulation of SIRT1.

Excessive ROS produced from the mitochondria is still regarded as one of the major factors for cumulative DNA damage to promoting aging. This mitochondrial free radical theory of cellular senescence is partly supported by the model of sublethal $\mathrm{H}_{2} \mathrm{O}_{2}$-induced replicative senescence in human diploid fibroblast [2, 3, 22]. Indeed, in our experiments, sublethal $\mathrm{H}_{2} \mathrm{O}_{2}$ increased significantly the number of senescent cells (Figures 1(d) and 1(f)), induced checkpoint kinase 2 activation (Figure 2(c)), and subsequently caused an irreversible growth arrest in G1 phase (Figures 2(a) and 2(b)). As a major and stable product formed by mitochondrial respiratory chain, excessive $\mathrm{H}_{2} \mathrm{O}_{2}$ can not only directly damage the integrity of DNA to cause genome instability but it can also be converted into hydroxyl radical, which injure mitochondrial membrane and lead to loss of $\Delta \Psi \mathrm{m}$. Consequently, loss of $\Delta \Psi \mathrm{m}$ further can cause dysfunction of the mitochondrial electron transport chain and result in generation of more intracellular ROS [3, 22, 23]. Indeed, as shown in our experiments, $\mathrm{H}_{2} \mathrm{O}_{2}$ induced loss of $\Delta \Psi \mathrm{m}$ (Figure 3) and caused generation of more intracellular ROS (Figure 4) in human diploid fibroblast. This suggested that mitochondrial dysfunction may be one of the reasons for acceleration of cellular senescence induced by sublethal $\mathrm{H}_{2} \mathrm{O}_{2}$.

In some studies, mitochondria-associated pathway can be manipulated to extend lifespan by pharmacological drugs, such as antioxidant and SIRT1-activtor resveratrol [24], antilipolytic acipimox [25], and antidiabetic metformin [26]. Berberine (BBR), the bioactive compound in the Chinese herb Rhizoma coptidis, had been reported as an 

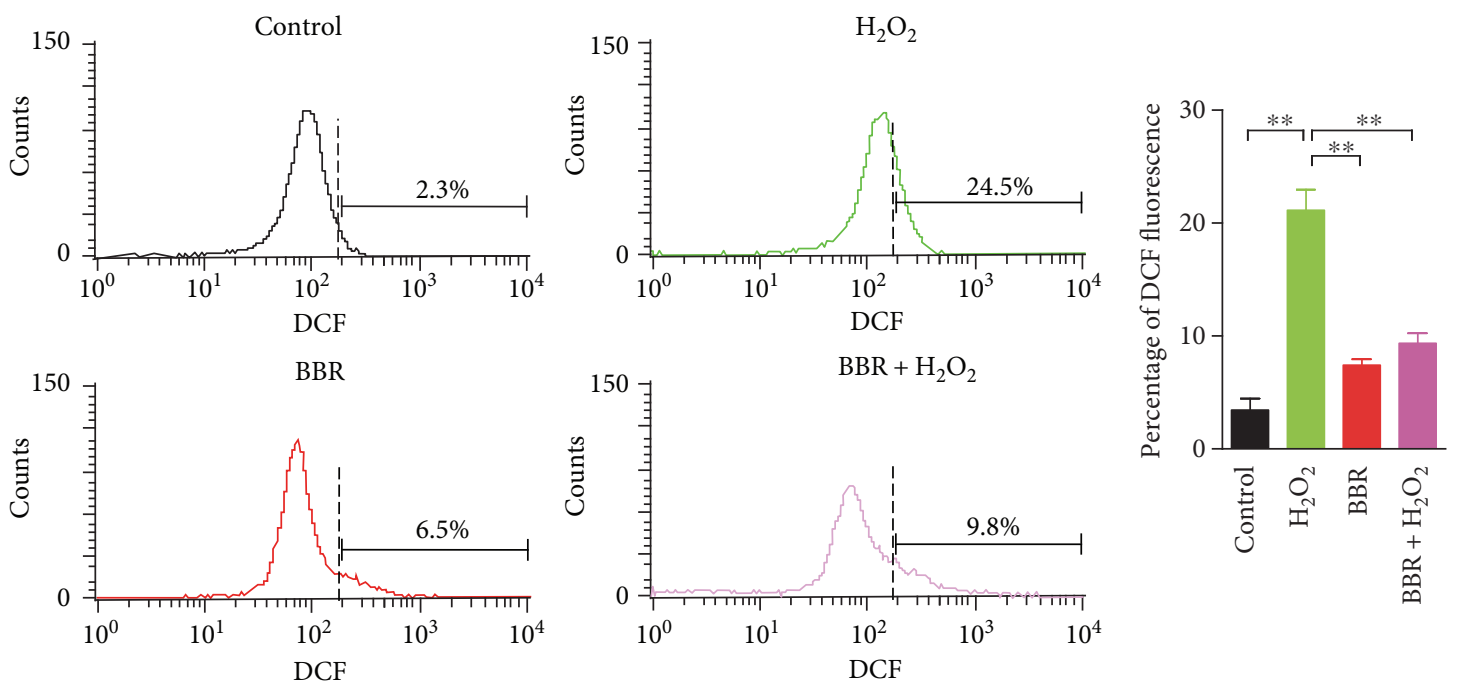

(a)

(b)

FIGURE 4: Protective effect of BBR on $\mathrm{H}_{2} \mathrm{O}_{2}$-induced intracellular ROS production in human diploid fibroblasts. 2BS cells were pretreated with or without $12 \mu \mathrm{mol} / \mathrm{L}$ BBR prior to a $2 \mathrm{hr}$ exposure of $200 \mu \mathrm{mol} / \mathrm{L} \mathrm{H}_{2} \mathrm{O}_{2}$, or treated with BBR alone as the Materials and Methods mentioned. (a) The diagram of fluorescence DCF detection with different treatments from flow cytometry analysis. (b) Histogram of the mean fluorescence intensity of DCF, reflecting the percentages of ROS generation in different treatment group. ${ }^{* *} p<0.01$. The results are representative of three separate experiments.

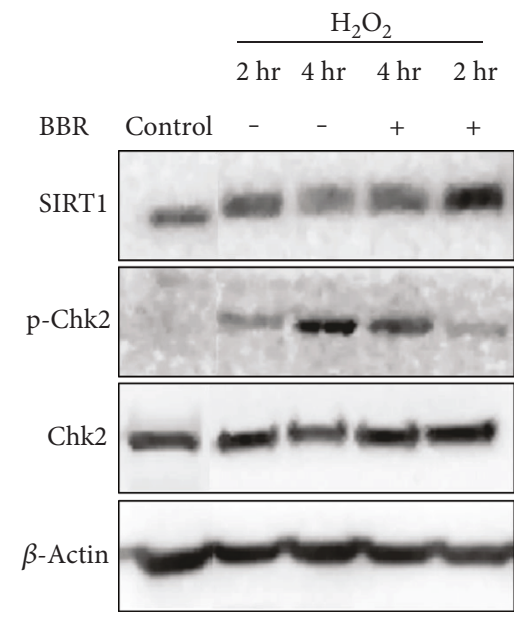

(a)
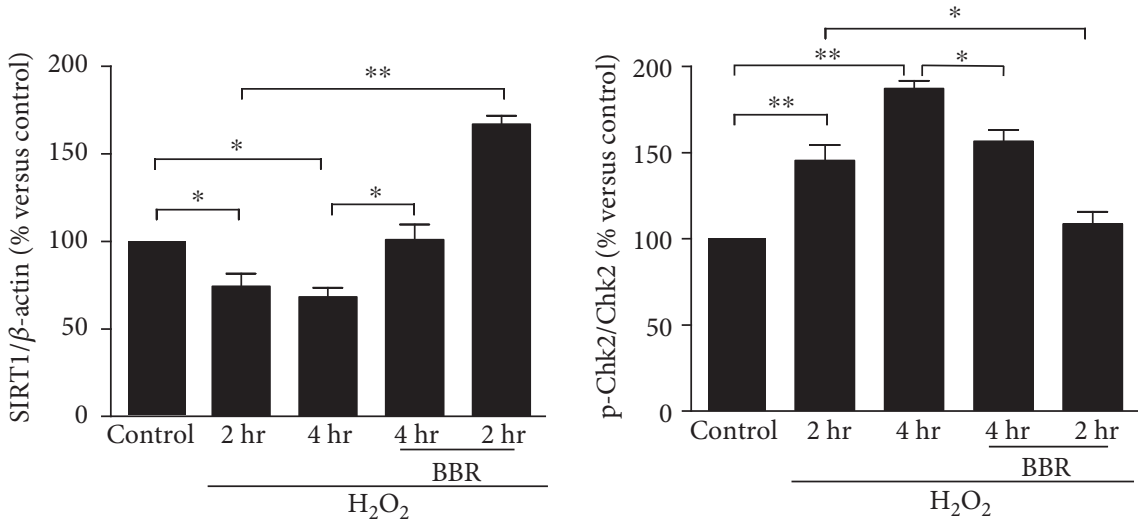

(b)

FIgURE 5: Protective effect of BBR on $\mathrm{H}_{2} \mathrm{O}_{2}$-induced reduction of SIRT1 expression and augment of phosphorylation of Chk2 in human diploid fibroblasts. 2BS cells were pretreated with $12 \mu \mathrm{mol} / \mathrm{L} \mathrm{BBR}$ for $12 \mathrm{hr}$ before a $2 \mathrm{hr}$ or $4 \mathrm{hr}$ exposure to $200 \mu \mathrm{mol} / \mathrm{L} \mathrm{H}_{2} \mathrm{O}_{2}$. (a) Sirt1 and phospho-Chk2 was detected by western blotting. (b) Relative expression levels of Sirt1 and phospho-Chk2 in cells with different treatment by gray analysis. ${ }^{*} p<0.05,{ }^{* *} p<0.01$. The results are representative of three separate experiments.

antidiabetic drug with a long history in china [8, 27]. Recently, it also was found that BBR had an antiaging effect by AMPK-mediated inhibition of mTOR signaling [11]. However, AMPK activation by BBR may be attributed to its inhibition of mitochondrial respiratory electron transport chain, which causes a decrease of ATP production and leads to an increase of AMP to ATP ratio [28, 29]. AMPK activation also enhance SIRT1 activity by $\mathrm{NAD}^{+}$ levels [30]. Intriguingly, in our study, the expression level of SIRT1 was increased in a time-dependent manner when fibroblasts were treated at a low concentration $(12 \mu \mathrm{M})$ of $\mathrm{BBR}$ (Figure S2). Moreover, the preconditioning of BBR at $12 \mu \mathrm{M}$ obviously decreased the amount of senescent cells in a dose-dependent manner measured by the activity of senescence-associated $\beta$-galactosidase (Figures 1(a), 1(b), $1(\mathrm{c})$, and $1(\mathrm{f})$ ), and partly reversed $\mathrm{H}_{2} \mathrm{O}_{2}$-induced $\mathrm{G} 1$ phase growth arrest (Figure 2(a)). These data suggested that upregulation of SIRT1 may be another antiaging mechanism of BBR. Actually, AMPK and SIRT1 are vital participators in cellular senescence by reciprocal regulation [29-32]. 
However, it was reported in many literature that BBR had a diphasic effect on different type of cells, such as protective effect on endothelial cells [33] and $\beta$ cells [34] or apoptosisinduced effect on cancer cells $[35,36]$. By MTT assay, we observed that BBR could protect cell from $\mathrm{H}_{2} \mathrm{O}_{2}$-induced growth inhibition at a low concentration $(\leq 12 \mu \mathrm{M})$, and at high concentration $(\geq 20 \mu \mathrm{M})$, BBR had no protective effect (Figure S1). Actually, this could be correlated with the concentration and intracellular distribution of BBR. BBR is a mitochondria-targeted cationic probe and can gather at the inner mitochondrial membrane by electrostatic interaction [37]. At a low concentration, BBR could mostly accumulate in the mitochondria and exhibit no cytotoxicity [38]. With an increase of concentration of BBR, the cellular localization of BBR distributed from the mitochondria to the cytoplasm and nuclei, which may inhibit cell growth and even induce cell death [39]. When targeted mitochondria are at low concentration, BBR could convert energy metabolism of cells into glycolysis by inhibition of mitochondrial respiratory chain $[28,38]$, which was indirectly reflected by a slight increase of intracellular ROS (Figure 4). Recently, evidence indicated the beneficial role of mitochondrial ROS in lifespan at physiological or low concentration under stress conditions $[40,41]$. It implied that low concentration of BBR may alert the mitochondria to trigger stress-mediated SIRT1 expression by an appropriate amount increase of intracellular ROS, and benefit fibroblasts to resist subsequent sublethal $\mathrm{H}_{2} \mathrm{O}_{2}$-induced stress.

SIRT1 is a master metabolic sensor and a mitochondria function protector by regulating some elements of proaging pathways, and delays the onset of age-related diseases $[13,14,42-45]$. Under oxidative stress, SIRT1 could exhibit antioxidative activity by upregulating expression of antioxidant enzymes [46, 47]. However, $\mathrm{H}_{2} \mathrm{O}_{2}$ could downregulate the expression level of SIRT1 by Chk2-HuR-mediated instability of SIRT1 mRNA [16]. Indeed, in our study, exposure to sublethal $\mathrm{H}_{2} \mathrm{O}_{2}$ induced mild downregulation of SIRT1 and Chk2 activation (Figures 2(c), 2(d), and 5(a)). But the $\mathrm{H}_{2} \mathrm{O}_{2}$-induced Chk2 activation was reduced significantly by pretreatment of BBR, accompanied by an obviously retard in downregulation of SIRT1 expression (Figure 5). These data implied that low concentration of BBR may also protect from reduction of SIRT1 expression by deactivating Chk2, which may be associated with BBR-induced upregulation of SIRT1.

Mitohormesis could be triggered by any insults including pharmacological intervention and induce the cellular stress response, and thereby protect against larger subsequent stresses [48]. More importantly, it was proposed that mitohormesis is a reason for benefits of ROS produced by lifespan-promoting interventions in cellular physiology under stress [49]. Recently, metformin, an antidiabetic drug, shows lifespan-extending properties by peroxiredoxin PRDX-2 related to ROS-mediated mitohormetic signalling pathway [26]. Based on our data, we speculate that the mitohormetic effect of BBR may be associated with the upregulation of SIRT1, which possibly is associated with a BBR-induced appropriate amount of increase of intracellular ROS. However, what is the mitochondrial retrograde signalling that induces SIRT1 expression during mitohormesis? Is ROS produced by low concentration of BBR really involved in mitohormesis as a signalling molecular? All of these questions will need to be answered by further deliberate experiments.

\section{Conclusions}

Our work revealed that a low-concentration preconditioning of BBR may exhibit antisenescence effect on $\mathrm{H}_{2} \mathrm{O}_{2}$-induced premature senescence of human diploid fibroblasts through the process of mitohormesis involved with SIRT1 upregulation, which elicits cytoprotective responses to resist subsequent $\mathrm{H}_{2} \mathrm{O}_{2}$-induced stress by decreasing activation of Chk2. In turn, this could protect against reduction of SIRT1 expression. This could give a hint that mitochondrialtargeted drugs like BBR can be potentially applied for aging-related diseases through mitohormesis.

\section{Conflicts of Interest}

The authors declare that there is no conflict of interest regarding the publication of this paper.

\section{Acknowledgments}

This work was supported by grants from the National Natural Science Foundation of China (no. 81373135), the support project for Talents of Science and Technology Innovation in universities of Henan (no. 15HASTIT040), and the Graduate Innovative Practice Base for Clinical Medicine of Xinxiang Medical University.

\section{References}

[1] D. Harman, "Aging: a theory based on free radical and radiation chemistry," Journal of Gerontology, vol. 11, no. 3, pp. 298-300, 1956.

[2] R. S. Balaban, S. Nemoto, and T. Finkel, "Mitochondria, oxidants, and aging," Cell, vol. 120, no. 4, pp. 483-495, 2005.

[3] S. Orrenius, V. Gogvadze, and B. Zhivotovsky, "Mitochondrial oxidative stress: implications for cell death," Annual Review of Pharmacology and Toxicology, vol. 47, pp. 143-183, 2007.

[4] Q. Chen and B. N. Ames, "Senescence-like growth arrest induced by hydrogen peroxide in human diploid fibroblast F65 cells," Proceedings of the National Academy of Sciences of the United States of America, vol. 91, no. 10, pp. 41304134, 1994.

[5] A. Trifunovic, A. Wredenberg, M. Falkenberg et al., "Premature ageing in mice expressing defective mitochondrial DNA polymerase," Nature, vol. 429, no. 6990, pp. 417-423, 2004.

[6] G. P. Dimri, X. Lee, G. Basile et al., "A biomarker that identifies senescent human cells in culture and in aging skin in vivo," Proceedings of the National Academy of Sciences of the United States of America, vol. 92, no. 20, pp. 9363-9367, 1995.

[7] Berberine, "Bureau CMMICoNMM," in Handbook of Effective Compositions in Plants. 1, pp. 12-18, People's Medical Publishing House, Beijing, 1991.

[8] B. Wang, Huangdi Neijing. 1, Ancient Books of Traditional Chinese Medicine Press, Beijing, 2003. 
[9] V. V. Navrotskaya, G. Oxenkrug, L. I. Vorobyova, and P. Summergrad, "Berberine prolongs life span and stimulates locomotor activity of Drosophila melanogaster," American Journal of Plant Sciences, vol. 3, no. 7A, pp. 1037-1040, 2012.

[10] H. D. Halicka, H. Zhao, J. Li et al., "Potential anti-aging agents suppress the level of constitutive DNA mage and mTOR-signaling," Aging (Albany NY), vol. 4, no. 12, pp. 952-965, 2012.

[11] H. Zhao, H. D. Halicka, J. Li, and Z. Darzynkiewicz, "Berberine suppresses gero-conversion from cell cycle arrest to senescence," Aging (Albany NY), vol. 5, no. 8, pp. 623-636, 2013.

[12] X. Zhu, X. Guo, G. Mao et al., "Hepatoprotection of berberine against hydrogen peroxide-induced apoptosis by upregulation of sirtuin 1," Phytotherapy Research, vol. 27, no. 3, pp. 417421, 2013.

[13] L. Bordone and L. Guarente, "Calorie restriction, SIRT1 and metabolism: understanding longevity," Nature Reviews Molecular Cell Biology, vol. 6, no. 4, pp. 298-305, 2005.

[14] H. Y. Cohen, C. Miller, K. J. Bitterman et al., "Calorie restriction promotes mammalian cell survival by inducing the SIRT1 deacetylase," Science, vol. 305, no. 5682, pp. 390-392, 2004.

[15] A. Furukawa, S. Tada-Oikawa, S. Kawanishi, and S. Oikawa, " $\mathrm{H}_{2} \mathrm{O}_{2}$ accelerates cellular senescence by accumulation of acetylated p53 via decrease in the function of SIRT1 by NAD+ depletion," Cellular Physiology and Biochemistry: International Journal of Experimental Cellular Physiology, Biochemistry, and Pharmacology, vol. 20, no. 1-4, pp. 45-54, 2007.

[16] K. Abdelmohsen, R. Pullmann Jr., A. Lal et al., "Phosphorylation of HuR by Chk2 regulates SIRT1 expression," Molecular Cell, vol. 25, no. 4, pp. 543-557, 2007.

[17] Z. Darzynkiewicz, F. Traganos, L. Staiano-Coico, J. Kapuscinski, and M. R. Melamed, "Interaction of rhodamine 123 with living cells studied by flow cytometry," Cancer Research, vol. 42, no. 3, pp. 799-806, 1982.

[18] L. V. Johnson, M. L. Walsh, B. J. Bockus, and L. B. Chen, "Monitoring of relative mitochondrial membrane potential in living cells by fluorescence microscopy," The Journal of Cell Biology, vol. 88, no. 3, pp. 526-535, 1981.

[19] H. Zhao, F. Traganos, A. P. Albino, and Z. Darzynkiewicz, "Oxidative stress induces cell cycle-dependent Mre11 recruitment, ATM and Chk2 activation and histone H2AX phosphorylation," Cell Cycle, vol. 7, no. 10, pp. 1490-1495, 2008.

[20] R. Curtis, B. J. Geesaman, and P. S. DiStefano, "Ageing and metabolism: drug discovery opportunities," Nature Reviews Drug Discovery, vol. 4, no. 7, pp. 569-580, 2005.

[21] G. Testa, F. Biasi, G. Poli, and E. Chiarpotto, "Calorie restriction and dietary restriction mimetics: a strategy for improving healthy aging and longevity," Current Pharmaceutical Design, vol. 20, no. 18, pp. 2950-2977, 2014.

[22] S. Zdanov, J. Remacle, and O. Toussaint, "Establishment of $\mathrm{H}_{2} \mathrm{O}_{2}$-induced premature senescence in human fibroblasts concomitant with increased cellular production of $\mathrm{H}_{2} \mathrm{O}_{2}$," Annals of the New York Academy of Sciences, vol. 1067, pp. 210-216, 2006.

[23] D. V. Ziegler, C. D. Wiley, and M. C. Velarde, "Mitochondrial effectors of cellular senescence: beyond the free radical theory of aging," Aging Cell, vol. 14, no. 1, pp. 1-7, 2015.

[24] M. Stefani, M. A. Markus, R. C. Lin, M. Pinese, I. W. Dawes, and B. J. Morris, "The effect of resveratrol on a cell model of human aging," Annals of the New York Academy of Sciences, vol. 1114, pp. 407-418, 2007.
[25] A. Donati, G. Cavallini, C. Carresi, Z. Gori, I. Parentini, and E. Bergamini, "Anti-aging effects of anti-lipolytic drugs," Experimental Gerontology, vol. 39, no. 7, pp. 1061-1067, 2004.

[26] W. De Haes, L. Frooninckx, R. Van Assche et al., "Metformin promotes lifespan through mitohormesis via the peroxiredoxin PRDX-2," Proceedings of the National Academy of Sciences of the United States of America, vol. 111, no. 24, pp. E2501-E2509, 2014.

[27] Y. X. Ni, "Therapeutic effect of berberine on 60 patients with type II diabetes mellitus and experimental research," Zhong Xi Yi Jie He Za Zhi, vol. 8, no. 12, pp. 711-713, 1988.

[28] N. Turner, J. Y. Li, A. Gosby et al., "Berberine and its more biologically available derivative, dihydroberberine, inhibit mitochondrial respiratory complex I: a mechanism for the action of berberine to activate AMP-activated protein kinase and improve insulin action," Diabetes, vol. 57, no. 5, pp. 1414-1418, 2008.

[29] C. Canto, Z. Gerhart-Hines, J. N. Feige et al., “AMPK regulates energy expenditure by modulating NAD+ metabolism and SIRT1 activity," Nature, vol. 458, no. 7241, pp. 10561060, 2009.

[30] F. Lan, J. M. Cacicedo, N. Ruderman, and Y. Ido, "SIRT1 modulation of the acetylation status, cytosolic localization and activity of LKB1; possible role in AMP-activated protein kinase activation," The Journal of Biological Chemistry, vol. 283, no. 41, pp. 27628-27635, 2008.

[31] C. Canto, L. Q. Jiang, A. S. Deshmukh et al., "Interdependence of AMPK and SIRT1 for metabolic adaptation to fasting and exercise in skeletal muscle," Cell Metabolism, vol. 11, no. 3, pp. 213-219, 2010.

[32] Y. Zu, L. Liu, M. Y. Lee et al., "SIRT1 promotes proliferation and prevents senescence through targeting LKB1 in primary porcine aortic endothelial cells," Circulation Research, vol. 106, no. 8, pp. 1384-1393, 2010.

[33] J. Guo, L. Wang, L. Wang et al., "Berberine protects human umbilical vein endothelial cells against LPS-induced apoptosis by blocking JNK-mediated signaling," Evidence-Based Complementary and Alternative Medicine, vol. 2016, Article ID 6983956, 11 pages, 2016.

[34] N. Gao, T. Y. Zhao, and X. J. Li, "The protective effect of berberine on $\beta$-cell lipoapoptosis," Journal of Endocrinological Investigation, vol. 34, no. 2, pp. 124-130, 2011.

[35] W. H. Hsu, Y. S. Hsieh, H. C. Kuo et al., "Berberine induces apoptosis in SW620 human colonic carcinoma cells through generation of reactive oxygen species and activation of JNK/ p38 MAPK and FasL," Archives of Toxicology, vol. 81, no. 10, pp. 719-728, 2007.

[36] H. L. Wu, T. Y. Chuang, A. Al-Hendy, M. P. Diamond, R. Azziz, and Y. H. Chen, "Berberine inhibits the proliferation of human uterine leiomyoma cells," Fertility and Sterility, vol. 103, no. 4, pp. 1098-1106, 2015.

[37] V. Mikes and V. Dadák, "Berberine derivatives as cationic fluorescent probes for the investigation of the energized state of mitochondria," Biochimica et Biophysica Acta, vol. 723, no. 2, pp. 231-239, 1983.

[38] J. Yin, Z. Gao, D. Liu, Z. Liu, and J. Ye, "Berberine improves glucose metabolism through induction of glycolysis," American Journal of Physiology Endocrinology and Metabolism, vol. 294, no. 1, pp. E148-E156, 2008.

[39] T. L. Serafim, P. J. Oliveira, V. A. Sardao, E. Perkins, D. Parke, and J. Holy, "Different concentrations of berberine result in 
distinct cellular localization patterns and cell cycle effects in a melanoma cell line," Cancer Chemotherapy and Pharmacology, vol. 61, no. 6, pp. 1007-1018, 2008.

[40] H. Kawagishi and T. Finkel, "Unraveling the truth about antioxidants: ROS and disease: finding the right balance," Nature Medicine, vol. 20, no. 7, pp. 711-713, 2014.

[41] K. M. Holmstrom and T. Finkel, "Cellular mechanisms and physiological consequences of redox-dependent signalling," Nature Reviews Molecular Cell Biology, vol. 15, no. 6, pp. 411-421, 2014.

[42] J. Luo, A. Y. Nikolaev, S. Imai et al., "Negative control of p53 by Sir2alpha promotes cell survival under stress," Cell, vol. 107, no. 2, pp. 137-148, 2001.

[43] A. Brunet, L. B. Sweeney, J. F. Sturgill et al., "Stress-dependent regulation of FOXO transcription factors by the SIRT1 deacetylase," Science, vol. 303, no. 5666, pp. 2011-2015, 2004.

[44] E. Nisoli, C. Tonello, A. Cardile et al., "Calorie restriction promotes mitochondrial biogenesis by inducing the expression of eNOS," Science, vol. 310, no. 5746, pp. 314-317, 2005.

[45] J. Huang, Q. Gan, L. Han et al., "SIRT1 overexpression antagonizes cellular senescence with activated ERK/S6k1 signaling in human diploid fibroblasts," PLoS One, vol. 3, no. 3, article e1710, 2008.

[46] Z. Ungvari, N. Labinskyy, P. Mukhopadhyay et al., "Resveratrol attenuates mitochondrial oxidative stress in coronary arterial endothelial cells," American Journal of Physiology. Heart and Circulatory Physiology, vol. 297, no. 5, pp. H1876H1881, 2009.

[47] R. R. Alcendor, S. Gao, P. Zhai et al., "Sirt1 regulates aging and resistance to oxidative stress in the heart," Circulation Research, vol. 100, no. 10, pp. 1512-1521, 2007.

[48] J. Yun and T. Finkel, "Mitohormesis," Cell Metabolism, vol. 19, no. 5, pp. 757-766, 2014.

[49] M. Ristow, "Unraveling the truth about antioxidants: mitohormesis explains ROS-induced health benefits," Nature Medicine, vol. 20, no. 7, pp. 709-711, 2014. 


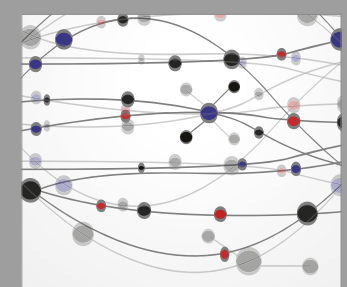

The Scientific World Journal
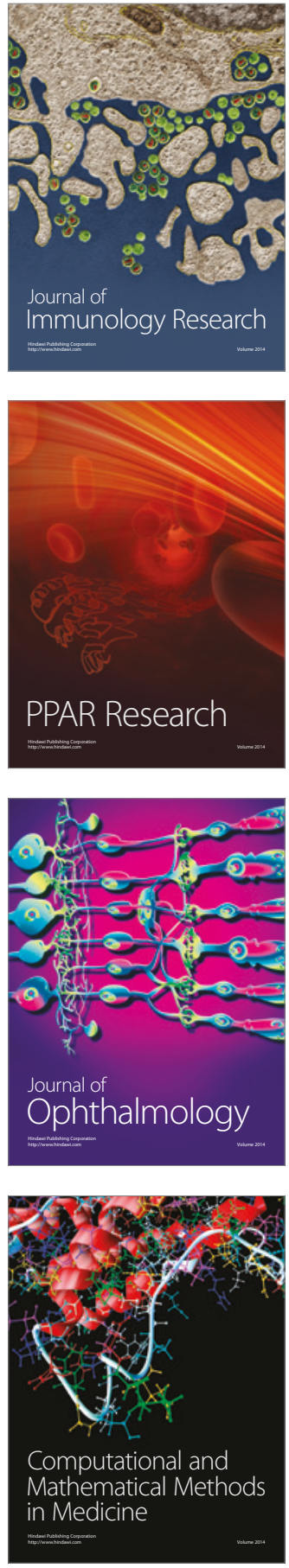

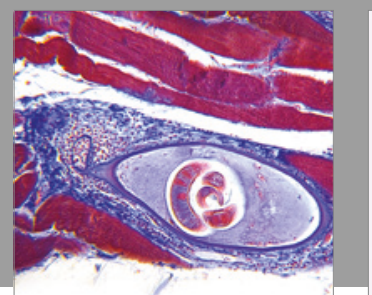

Gastroenterology Research and Practice
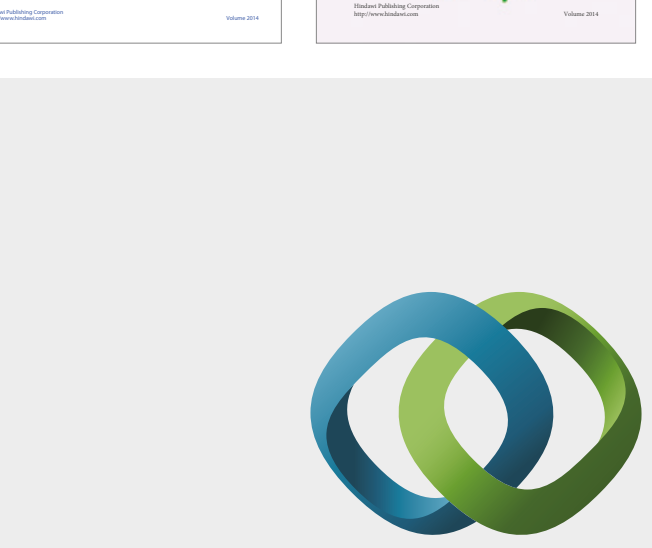

\section{Hindawi}

Submit your manuscripts at

https://www.hindawi.com
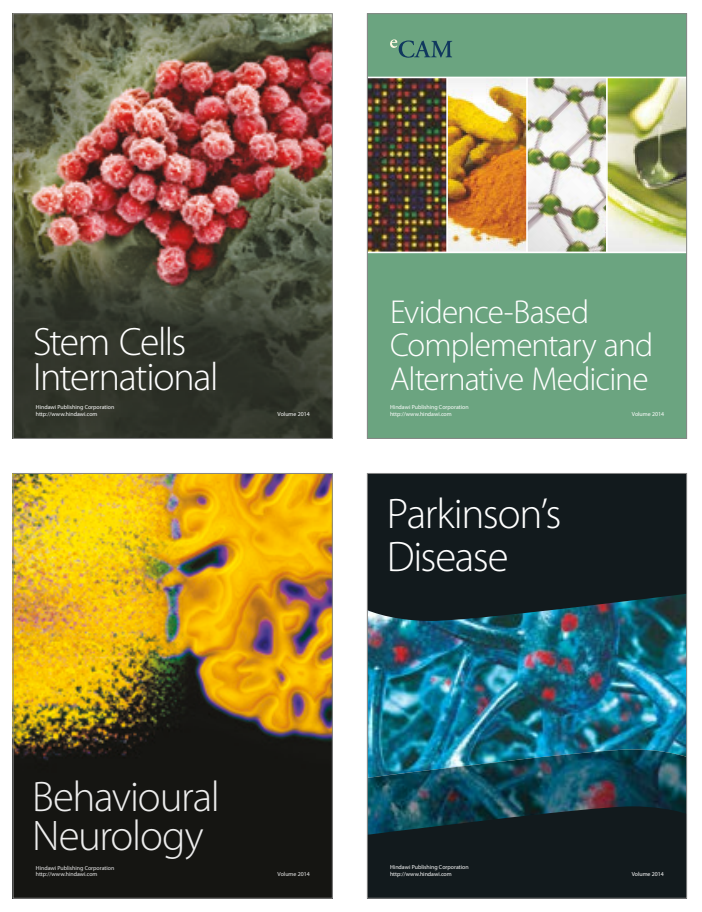
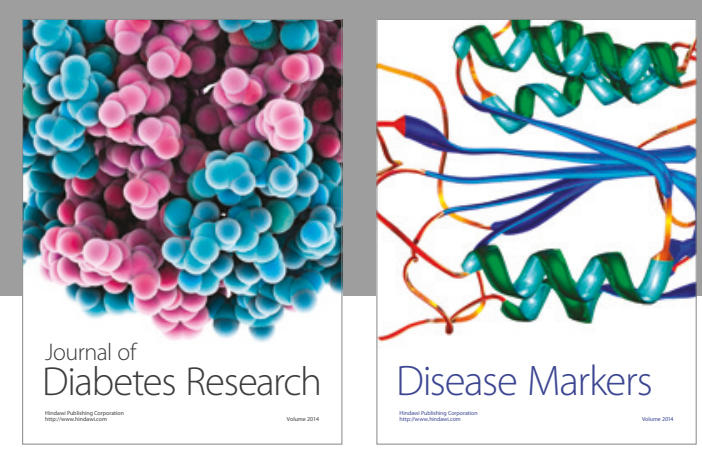

Disease Markers
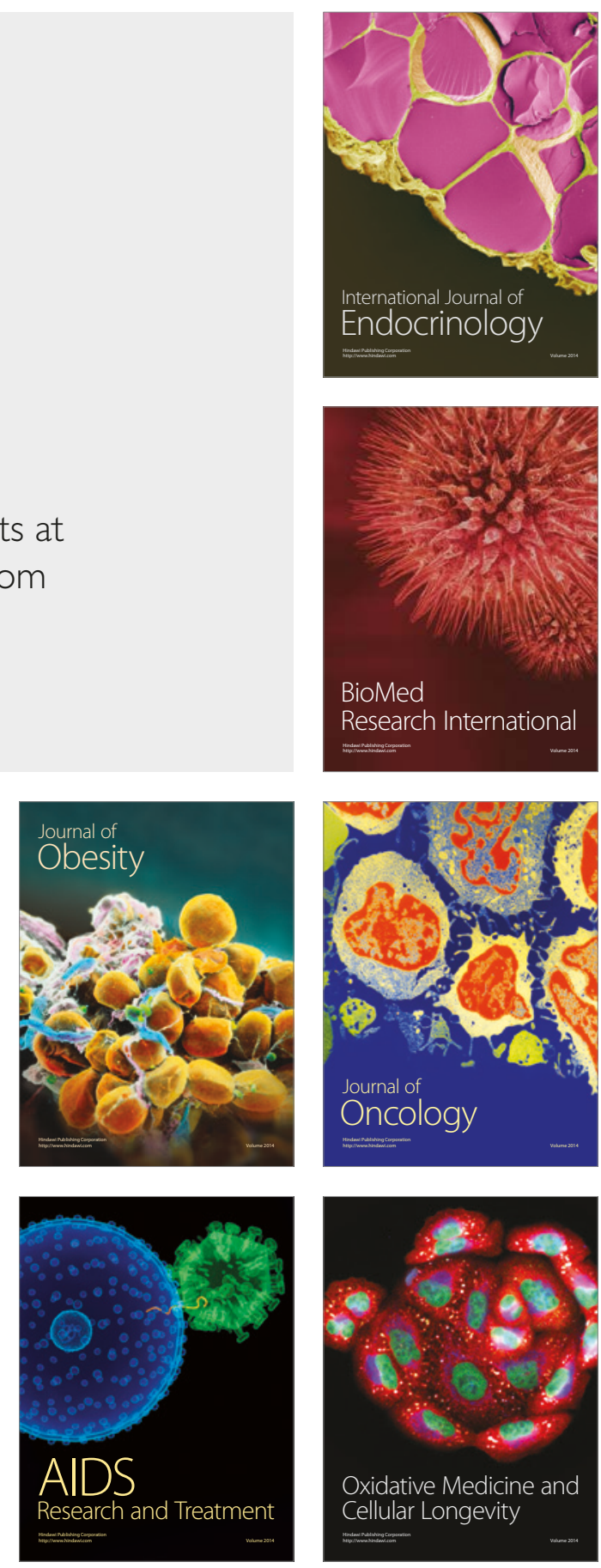